Technical Innovations in Microneurosurgery | Tomlinson SB et al.

\title{
Innovations in the Art of Microneurosurgery for Reaching Deep-Seated Cerebral Lesions
}

(invited submission for "Innovation in Neurosurgery" special issue)

Samuel B. Tomlinson, BA, ${ }^{\mathrm{a}, \mathrm{b}}$ Benjamin K. Hendricks, MD, ${ }^{\mathrm{a}}$ Fabio Torregrossa, MS, ${ }^{\mathrm{c}}$ Giovanni Grasso, MD, PhD, ${ }^{\mathrm{c}}$ Aaron A. Cohen-Gadol, MD, MSc, MBA ${ }^{\mathrm{a}, \mathrm{d}, *}$

${ }^{\mathrm{a}}$ Neurosurgical Atlas, Indianapolis, Indiana, USA; ${ }^{\mathrm{b}}$ School of Medicine and Dentistry, University

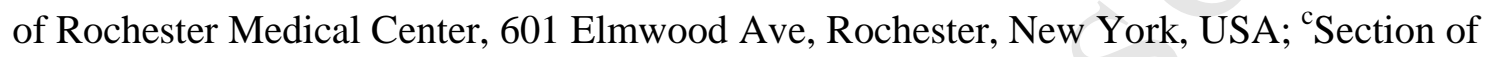
Neurosurgery, Department of Biomedicine, Neurosciences and Advanced Diagnostics, University of Palermo, Piazza Marina, 61, Palermo, Italy; and ${ }^{\mathrm{d}}$ Goodman Campbell Brain and Spine, Department of Neurological Surgery, Indiana University School of Medicine, 355 W 16th Street, Indianapolis, Indiana, USA

Email addresses: Samuel Tomlinson, samuel_tomlinson@urmc.rochester.edu; Benjamin Hendricks, ben.k.hendricks@me.com; Fabio Torregrossa, fabiotorregrossa00@gmail.com; Giovanni Grasso, giovanni.grasso@unipa.it; and Aaron Cohen-Gadol, acohenmd@gmail.com *Corresponding author: Aaron Cohen-Gadol, MD, MSc, MBA, Goodman Campbell Brain and Spine, Department of Neurological Surgery, Indiana University, 355 W 16th Street, Suite 5100, Indianapolis, IN 46202; acohenmd@gmail.com.

\section{Declarations of Interest: none}

This is the author's manuscript of the article published in final edited form as:

Tomlinson, S. B., Hendricks, B. K., Torregrossa, F., Grasso, G., \& Cohen-Gadol, A. A. (2019). Innovations in the Art of Microneurosurgery for Reaching Deep-Seated Cerebral Lesions (invited submission for "Innovation in Neurosurgery" special issue). World Neurosurgery. https://doi.org/10.1016/j.wneu.2019.06.210 
Technical Innovations in Microneurosurgery | Tomlinson SB et al.

Short Title: Technical Innovations in Microneurosurgery

Key Words: Innovation; Microneurosurgery; Neurosurgical Atlas; Operative technique;

Surgical corridors 
4

\section{Innovations in the Art of Microneurosurgery for Reaching Deep-Seated Cerebral Lesions}

6 (Invited submission for "Innovation in Neurosurgery" special issue)

\section{Abbreviations}

10 AVM, arteriovenous malformation; MTR, mediobasal temporal region; OGM, olfactory groove 11 meningioma; ON, optic nerve; PITTA, posterior interhemispheric transfalcine transprecuneus approach; SCTT, supracerebellar transtentorial; SSS, superior sagittal sinus 


\section{Abstract}

Deep-seated cerebral lesions have fascinated and frustrated countless surgical innovators since the dawn of the microneurosurgical era. To determine the optimal approach, the microneurosurgeon must take into account the characteristics and location of the pathological lesion as well as the operator's range of technical expertise. Increasingly, microneurosurgeons must select between multiple operative corridors that can access to the surgical target. Innovative trajectories have emerged for many indications that provide more flexible operative angles and superior exposure but result in longer working distances and more technically demanding maneuvers. In this article, we highlight 4 innovative surgical corridors and compare their strengths and weaknesses against those of more conventional approaches. Our goal is to use these examples to illustrate the following principles of microneurosurgical innovation: (1) discover more efficient and flexible exposures with superior working angles; (2) ensure maximal early protection of critical neurovascular structures; and (3) effectively handle target pathology with minimal disruption of normal tissues. 


\section{Introduction}

Deep-seated cerebral lesions often test the limits of traditional microneurosurgical skills.

Innovators in microneurosurgery focus on developing and refining flexible operative corridors to reach the most challenging deep-seated lesions. Technical challenge is entertained in an effort to preserve healthy neurovascular structures and effectively handle the surgical target. Surgeons operating within this frontier must balance the demand for technical innovation against the risks borne by the patients undergoing the novel surgical intervention. ${ }^{1}$

The senior authors of this article have pursued innovative approaches to deep-seated lesions, often brushing against the grain of existing dogma. The motivation to persevere in the face of uncertainty arises from the operator's commitment to optimizing the surgical intervention offered to every patient and a belief in his or her own ability to navigate uncharted territory. The purpose of this article is to illustrate the process of microneurosurgical innovation by examining the following 4 surgical approaches in relation to more conventional routes (Table 1):

1) Contralateral posterior interhemispheric transfalcine transprecuneus approach (PITTA) to the periatrial region, traditionally reached via the lateral transcortical route;

2) Paramedian supracerebellar transtentorial (SCTT) approach to the mediobasal temporal region (MTR), traditionally accessed via the lateral transsylvian or transcortical route; 
3) Lateral (paramedian) supracerebellar approach to the midline pineal region, commonly approached via midline suboccipital craniotomy; and (1)

4) Extended pterional craniotomy for large midline anterior skull base lesions, traditionally accessed via bifrontal craniotomy.

These technical refinements share core principles of microneurosurgical innovation: (1) discover less invasive and more flexible exposures while unlocking superior working angles; (2) protect normal anatomy; and (3) efficiently handle of target pathology using dynamic retraction. In the experience of the senior authors, the learning curve for these surgical corridors can be overcome through training in the cadaver laboratory and with approximately 10 operative cases.

\section{Contralateral PITTA}

Lesions arising in the periatrial region of the lateral ventricle (eg, arteriovenous malformations [AVMs], meningiomas, choroid plexus papillomas) are notoriously difficult to access. Critical vascular structures that must be negotiated include the anterior and posterior choroidal arteries, pericallosal arteries, internal cerebral veins, and the straight sinus, among others. The depth of periatrial lesions also places the overlying eloquent cortex and white matter pathways at risk.

Standard ipsilateral interhemispheric and transcortical approaches to the periatrial region suffer limitations related to the need for extensive brain retraction and parenchymal transgression and the inaccessibility of lesions with significant lateral extension..$^{2-4}$ In the 1990 s, Atul Goel published the first description of the contralateral transfalcine approach for resection of deep- 
seated intrinsic tumors. ${ }^{5}$ A cadaveric study by Wang et al. ${ }^{6}$ revealed the promise of contralateral PITTA for accessing the periatrial region, which was later used by Zhu and colleagues ${ }^{7}$ for resection of periatrial meningioma in two patients. That group published their favorable experience with this operative route in a series of 10 patients with periatrial lesions. ${ }^{2}$ Details of the PITTA technique can be found in the report on a 14-patient series by Bohnstedt et al. ${ }^{3}$

The evolution of the PITTA for periatrial lesions demonstrates key principles of microneurosurgical innovation (Figure 1). The approach capitalizes on a natural plane to access the surgical target, thus avoiding risks associated with cortical transgression. Strategic use of gravity retraction and cerebrospinal fluid drainage, combined with the favorable "cross-court" view, minimizes the need for brain retraction and offers flexible working angles for reaching lesions with lateral extension. The inferior working angle of the PITTA facilitates early access to the vascular pedicle, a requisite for managing highly vascular lesions that arise in this region (eg, meningiomas, AVMs).

Of course, these advantages come with the cost of longer working distances, less-familiar operative anatomy, a technically demanding surgical corridor, and risks placed on the normal contralateral hemisphere. The surgeon, therefore, must weigh the advantages and disadvantages of this approach against his or her technical expertise. In the senior author's experience, ${ }^{3}$ the PITTA is superior to conventional ipsilateral approaches (eg, anterior transsylvian, posterior transcortical or transcallosal, lateral transtemporal or subtemporal) for the majority of periatrial lesions, particularly those that involve the lateral regions of the trigone. 


\section{Paramedian SCTT Approach to the Posterior MTR}

101 When accessing the MTR, surgeons must negotiate the eloquent cortices and vasculature of the

102

103

104

105

106

107 meningiomas. ${ }^{8,12,14-19}$

temporal lobe. Conventional approaches to this region include variations of the lateral transtemporal and subtemporal trajectories, the transsylvian-transcisternal alternative, and, less commonly, the interhemispheric parieto-occipital route. ${ }^{8}$ Each of these approaches places the supratentorial structures at risk of injury or transgression. The subtemporal approach requires significant upward retraction on the temporal lobe and threatens the critical vein of Labbé, whereas the transtemporal corticotomy approach transgresses the posterior temporal neocortex and interrupts the temporal optic radiations. The transsylvian-transcisternal route provides satisfactory access to the anterior MTR down a long, narrow operative corridor but enables minimal exposure of the posterior MTR. ${ }^{9}$

The paramedian SCTT approach has been recognized since the 1970s as a useful corridor to the posterior MTR that minimizes risk to supratentorial structures (Figure 2). ${ }^{10-12}$ Voigt and Yasargil ${ }^{13}$ introduced this approach in a seminal case involving resection of a left posterior hippocampal cavernous malformation. Türe and colleagues ${ }^{11}$ contributed a vital account of the operative anatomy for this corridor in an influential study of 25 cadaver specimens and 15 patients with MTR lesions. Subsequent technical innovation extended the use of this corridor for management of diverse intrinsic MTR lesions (eg, gliomas, hippocampal sclerosis, parahippocampal gangliogliomas), vascular lesions (eg, AVMs, posterior cerebral artery aneurysms), and, most recently, extra-axial pathology such as medial tentorial 
123

124

125

126

127

128

129

132

133

134

135

136

137

138

139

140

141

142

143

144

Intuitive advantages of the SCTT approach relate to the gentle handling of eloquent structures in the supratentorial compartment, particularly when the dominant temporal lobe is implicated. The approach minimizes risk to functional language cortices and obviates the need for temporal corticotomy. Indications for SCTT include most MTR lesions situated posterior to the uncus, because lesions that extend anteriorly past the cerebral peduncles are poorly exposed through this corridor. For most MTR tumors, exposure of the tumor dome via the SCTT approach is relatively late and thus threatens adherent vessels. Another limitation is the narrowness of the operative corridor and the longer working distance compared to the more generous exposures afforded by transsylvian or transcortical routes. As such, this technically demanding approach should be used judiciously after the relevant operative anatomy is mastered in the laboratory.

\section{Lateral (Paramedian) Supracerebellar Approach to the Midline Pineal Region}

Multiple approaches to the midline pineal region have been explored since the pioneering work of Walter Dandy, Hermann Oppenheim, and Fedor Krause in the early 20th century. ${ }^{20}$ Today, the midline supracerebellar infratentorial approach described by $\operatorname{Stein}^{21}$ is perhaps the most familiar and widely used microneurosurgical corridor for accessing midline pineal lesions. Compared to supratentorial alternatives (eg, the posterior interhemispheric transcallosal, occipital transtentorial, and transcortical transventricular routes), the midline supracerebellar approach exploits the natural tentorial plane and provides the most direct access to the midline pineal region. Through this flexible midline corridor, the surgeon can efficiently access the pineal region, supralateral pons, posterolateral dorsal midbrain, and third ventricle. 
145 Unavoidable limitations of the midline supracerebellar infratentorial approach have led the

146 senior author to mostly abandon this technique in favor of the unilateral (paramedian) variation

147 introduced by Yasargil. ${ }^{22}$ Compared to the paramedian approach, the midline trajectory places a

148 greater number of midline vermian and paravermian bridging veins at risk of injury or sacrifice

149 (the precentral vein is often sacrificed to facilitate exposure through the median route). ${ }^{23}$ Due to

150 the steep angle of the cerebellum at the midline, significant retraction is necessary to achieve

151 satisfactory exposure, and the patient is typically subjected to the risks associated with the sitting

152 position (eg, venous air embolism, hemodynamic instability) to take advantage of gravity

153 retraction. Inferiorly located lesions are regularly obscured by the apex of the culmen, and lateral

154 visualization is limited by the unfavorable slope of the medial tentorium. ${ }^{24,25}$

156 The paramedian supracerebellar infratentorial approach is a technical variation that overcomes

157 shortcomings of the midline trajectory (Figure 3). A comprehensive overview of this approach

158 can be found elsewhere. ${ }^{23,25,26}$ Advantages of the paramedian variant begin with the less invasive

159 craniotomy that exposes only 1 cerebellar hemisphere and transverse sinus without exposing the

160 torcula (Figure 3E). Because the paramedian approach facilitates an expanded cross-court access

161 to the contralateral pineal region, a left-sided craniotomy avoids any risk to the typically

162 dominant right transverse sinus. The favorable slope of the lateral cerebellum allows for more

163 flexible working angles and enhanced exposure of inferiorly situated lesions. The relative

164 scarcity of bridging veins in the paramedian territory, which lessens the risk of injury and

165 postoperative venous congestion, is yet another advantage. Of note, the paramedian approach is a

166 less direct, oblique route to the midline pineal region and thus challenges the surgeon with longer

167 working distances, a narrower surgical corridor, and potentially disorienting unfamiliar anatomy. 


\section{Extended Pterional Craniotomy for Large Midline Anterior Skull Base Lesions}

170 The ideal approach for large midline skull base lesions of the anterior fossa is a topic of

171 considerable debate. ${ }^{27}$ The subfrontal route via bifrontal craniotomy is the classic approach for

172 midline parafalcine lesions, particularly those that invade the anterior skull base. Advantages of

173 bifrontal craniotomy include the generous exposure and flexible working angles, although the

174 approach violates the frontal sinuses and provides late access to critical dorsal neurovascular

175 structures. In the era of microneurosurgical innovation, several less invasive alternatives to the

176 bifrontal craniotomy have been advocated, each of which has unique strengths and weaknesses.

177

178 We believe that the vast majority of intradurally confined midline anterior fossa lesions of any size are optimally approached through an extended pterional or lateral supraorbital craniotomy. The technical advantages of the extended pterional approach for large vascular anterior midline skull base tumors are numerous. ${ }^{27}$ The operative anatomy is familiar to all neurosurgeons, and the lateral trajectory facilitates early identification and protection of the optic nerve, internal carotid artery, and anterior cerebral arteries through the transsylvian avenue. Early brain relaxation can be achieved by opening the prechiasmatic and carotid cisterns, and brain retraction can be limited to the nondominant frontal lobe. The anterior portion of the superior sagittal sinus (SSS), typically sacrificed during the bifrontal approach, can be spared with the lateral trajectory.

Despite the observation that sacrifice of the anterior portion of the SSS can be performed without adverse sequelae, clinical accounts of venous infarction after anterior SSS ligation have been published. $^{28}$ 
The pterional transsylvian approach has been shown to be a safe, versatile route for management of giant olfactory groove meningiomas (OGMs). ${ }^{29}$ For these lesions, the pterional route provides a better and wider exposure of the tumor through a transsylvian route, allowing earlier control of the anterior cranial base and critical neurovascular structures located at the posterior pole of the tumor. Furthermore, in a series of patients with giant OGMs for whom long-term follow-up was performed, Grasso and colleagues ${ }^{29}$ found that the pterional transsylvian approach achieved low rates of morbidity and death, minimal parenchymal damage as assessed by a magnetic resonance imaging-based quantitative analysis, and a low recurrence rate. In a retrospective case series involving 99 patients with OGM, the pterional approach was found to achieve an extent of resection similar to that of the bifrontal approach (Simpson grade I-II: 80\% [bifrontal] and 81\% [pterional]) and a lower rate of life-threatening complications (eg, retraction-related brain swelling, bleeding, and ischemia). ${ }^{30}$ These data align with the subjective experience of the senior authors, who have largely forsaken the bifrontal craniotomy for midline anterior skull base tumors unless significant bony invasion is apparent.

\section{Conclusions}

Innovation in microneurosurgery has vastly expanded the surgeon's armamentarium for accessing deep-seated cerebral lesions through more effective and less invasive surgical corridors. As a consequence, modern neurosurgeons increasingly face the challenge of selecting between multiple trajectories capable of reaching the surgical target. Evaluating the relative advantages and disadvantages of each candidate approach is central to the art of microneurosurgery. 
214 The surgeon can frequently achieve superior exposure and more flexible operative angles

215 through more modern surgical corridors if the attendant technical demands (eg, longer working

216 distance, less familiar anatomy) can be satisfied. The goals of technical innovation in

217 microneurosurgery include reducing manipulation of normal anatomy, achieving optimal

218 working angles, and securing early protection of vital neurovascular structures. The advancement

219 of modern technologies, such as high-resolution neuroimaging, virtual reality, endoscopic

220 capabilities, and other noninvasive techniques, combined with a burgeoning scientific literature,

221 should facilitate rapid progress in microneurosurgical innovation for decades to come.

\section{Acknowledgments}

224 We acknowledge the generous support of the Samerian Foundation.

\section{Funding Sources}

227 This research did not receive any specific grant from funding agencies in the public, commercial, or not-for-profit sectors. 
232 1. Cohen-Gadol AA. The art of microneurosurgery and passion for technical excellence. $J$ Neurosurg. 2018;130:1023-1027. doi:10.3171/2018.9.JNS182475.

2. Xie T, Sun C, Zhang X, et al. The contralateral transfalcine transprecuneus approach to the atrium of the lateral ventricle: operative technique and surgical results. Neurosurgery. 2015;11:110-117. doi:10.1227/NEU.0000000000000643.

3. Bohnstedt BN, Kulwin CG, Shah MV, Cohen-Gadol AA. Posterior interhemispheric transfalcine transprecuneus approach for microsurgical resection of periatrial lesions: indications, technique, and outcomes. J Neurosurg. 2015;123:1045-1054. doi:10.3171/2015.3.JNS14847.

4. Kawashima M, Li X, Rhoton AL, Jr, et al. Surgical approaches to the atrium of the lateral ventricle: microsurgical anatomy. Surg Neurol. 2006;65:436-445. doi: 10.1016/j.surneu.2005.09.033.

244 5. Goel A. Transfalcine approach to a contralateral hemispheric tumour. Acta Neurochir (Wien). 1995;135:210-212.

246 6. Wang S, Salma A, Ammirati M. Posterior interhemispheric transfalx transprecuneus approach to the atrium of the lateral ventricle: a cadaveric study. J Neurosurg. 
249 7. Zhu W, Xie T, Zhang X, et al. A solution to meningiomas at the trigone of the lateral ventricle using a contralateral transfalcine approach. World Neurosurg. 2013;80:167172. doi:10.1016/j.wneu.2012.08.010.

252

253

254

255

256

257

8. Ansari SF, Young RL, Bohnstedt BN, Cohen-Gadol AA. The extended supracerebellar transtentorial approach for resection of medial tentorial meningiomas. Surg Neurol Int. 2014;5:35. doi:10.4103/2152-7806.128918.

9. Campero A, Troccoli G, Martins C, et al. Microsurgical approaches to the medial temporal region: an anatomical study. Neurosurgery. 2006;59:ONS279-ONS307. doi:1227/01.NEU.0000223509.21474.2E.

10. de Oliveira JG, Parraga RG, Chaddad-Neto F, Ribas GC, de Oliveira EP. Supracerebellar transtentorial approach—resection of the tentorium instead of an opening-to provide broad exposure of the mediobasal temporal lobe: anatomical aspects and surgical applications: clinical article. J Neurosurg. 2012;116:764-772. doi:10.3171/2011.12.JNS111256.

11. Türe U, Harput MV, Kaya AH, et al. The paramedian supracerebellar-transtentorial approach to the entire length of the mediobasal temporal region: an anatomical and clinical study. J Neurosurg. 2012;116:773-791. doi:10.3171/2011.12.JNS11791.

12. Yonekawa Y, Imhof HG, Taub E, et al. Supracerebellar transtentorial approach to posterior temporomedial structures. J Neurosurg. 2001;94:339-345. doi:10.3171/jns.2001.94.2.0339. 
13. Voigt K, Yasargil MG. Cerebral cavernous haemangiomas or cavernomas. Incidence, pathology, localization, diagnosis, clinical features and treatment. Review of the literature and report of an unusual case. Neurochirurgia (Stuttg). 1976;19:59-68. doi:10.1055/s0028-1090391.

\section{Moftakhar R, Izci Y, Baskaya MK. Microsurgical anatomy of the supracerebellar} transtentorial approach to the posterior mediobasal temporal region: technical considerations with a case illustration. Neurosurgery. 2008;62:1-7. doi:10.1227/01.neu.0000317367.61899.65.

15. Uchiyama N, Hasegawa M, Kita D, Yamashita J. Paramedian supracerebellar transtentorial approach for a medial tentorial meningioma with supratentorial extension: technical case report. Neurosurgery. 2001;49:1470-1473. doi:10.1097/00006123$200112000-00036$.

16. Watanabe T, Katayama Y, Fukushima T, Kawamata T. Lateral supracerebellar transtentorial approach for petroclival meningiomas: operative technique and outcome. $J$ Neurosurg. 2011;115:49-54. doi:10.3171/2011.2.JNS101759.

17. Chaddad-Neto F, da Costa MDS, Caramanti RL, et al. Transtentorial approach for parahippocampal gyrus arteriovenous malformation resection: 3-dimensional operative video. Oper Neurosurg (Hagerstown). 2019;16:E83-E84. doi:10.1093/ons/opy294.

18. Manilha R, Harput VM, Ture U. The paramedian supracerebellar-transtentorial approach for a tentorial incisura meningioma: 3-dimensional operative video. Oper Neurosurg (Hagerstown). 2018;15:102. doi:1093/ons/opx250. 
19. Campero A, Ajler P, Rica C, Rhoton A, Jr. Cavernomas and arteriovenous malformations in the mesial temporal region: microsurgical anatomy and approaches. Oper Neurosurg (Hagerstown). 2017;13:113-123. doi: 10.1227/NEU.0000000000001239.

20. Little KM, Friedman AH, Fukushima T. Surgical approaches to pineal region tumors. $J$ Neurooncol. 2001;54:287-299.

21. Stein BM. The infratentorial supracerebellar approach to pineal lesions. J Neurosurg. 1971;35:197-202.

22. Yasargil MG. Microneurosurgery. Stuttgart, Germany: Georg Thieme; 1984.

23. La Pira B, Sorenson T, Quillis-Quesada V, Lanzino G. The paramedian supracerebellar infratentorial approach. Acta Neurochir (Wien). 2017;159:1529-1532. doi:10.1007/s00701-017-3196-y.

24. Kodera T, Bozinov O, Surucu O, et al, Neurosurgical venous considerations for tumors of the pineal region resected using the infratentorial supracerebellar approach. J Clin Neurosci. 2011;18:1481-1485. doi:10.1016/j.jocn.2011.02.035.

25. Kulwin C, Matsushima K, Malekpour M, Cohen-Gadol AA. Lateral supracerebellar infratentorial approach for microsurgical resection of large midline pineal region tumors: techniques to expand the operative corridor. J Neurosurg. 2016;124:269-276. doi:10.3171/2015.2.JNS142088. 
308

309

310

311

312

313

314

315

26. Rey-Dios R, Cohen-Gadol AA. A surgical technique to expand the operative corridor for supracerebellar infratentorial approaches: technical note. Acta Neurochir (Wien). 2013;155:1895-1900. doi:10.1007/s00701-013-1844-4.

27. Bitter AD, Stavrinou LC, Ntoulias G, et al. The role of the pterional approach in the surgical treatment of olfactory groove meningiomas: a 20-year experience. J Neurol Surg B Skull Base. 2013;74:97-102. doi:10.1055/s-0033-1333618.

28. Paterniti S, Fiore P, Levita A, La Camera A, Cambria S. Venous saving in olfactory meningioma's surgery. Clin Neurol Neurosurg. 1999;101:235-237.

29. Tomasello F, Angileri FF, Grasso G, et al. Giant olfactory groove meningiomas: extent of frontal lobes damage and long-term outcome after the pterional approach. World Neurosurg. 2011;76:311-317; discussion 255-258. doi:10.1016/j.wneu.2011.03.021.

30. Pallini R, Fernandez E, Lauretti L, et al. Olfactory groove meningioma: report of 99 cases surgically treated at the Catholic University School of Medicine, Rome. World Neurosurg. 2015;83:219-31.e1-219-31.e3. doi:10.1016/j.wneu.2014.11.001. 
Figure 1. Contralateral posterior interhemispheric transfalcine transprecuneus approach (PITTA) for periatrial lesions. (A) Cross-court approach to the contralateral atrium provided by the PITTA (green). The ipsilateral transcallosal/transcortical approach (red) requires significant retraction of the ipsilateral central lobule, particularly for accessing lesions with lateral periatrial extension. (B) Operative technique requiring interhemispheric dissection and Tshaped incision of the falx cerebri. (C) Axial T1-weighted magnetic resonance images (MRI) of representative left periatrial lesions that might be suitable for the PITTA: glioma (left), meningioma (center), and arteriovenous malformation (right). With permission from The Neurosurgical Atlas by Aaron Cohen-Gadol, MD.

\section{Figure 2. Paramedian supracerebellar transtentorial (SCTT) approach to the posterior} mediobasal temporal region (MTR). (A) Approach trajectory (green arrow). (B) Tentorial incision with retraction sutures used to mobilize the incised tentorial flaps. The deep locations of the lateral ventricle (blue) and hippocampus (yellow) are outlined. (C) Recent extensions of this operative corridor facilitate resection of medial tentorial meningiomas. Note the proximity to the trochlear nerve (inset), which must be protected during dissection of the tentorial incisura. (D) T1-weighted MRI images of a metastatic adenocarcinoma of the left parahippocampal gyrus than can be reached with the SCTT approach. With permission from The Neurosurgical Atlas by Aaron Cohen-Gadol, MD.

Figure 3. Paramedian supracerebellar infratentorial approach to the midline pineal region. (A) Illustration of the paramedian trajectory. (B) Sagittal illustration of a midline pineal region tumor. (C) Early operative view after left paramedian craniotomy, durotomy, and placement of 
tentorial retraction sutures. (D) Magnetic resonance images of representative lesions accessible via the paramedian supracerebellar infratentorial trajectory: germ cell tumor (left) and pineoblastoma (right). (E) The midline approach requires a more invasive bilateral craniotomy with exposure of the torcula and places more vermian and paravermian bridging veins at risk $(\mathrm{F})$. (G) The paramedian approach requires less retraction of the culmen and offers more flexible working angles and improved inferior and lateral visualization. With permission from The Neurosurgical Atlas by Aaron Cohen-Gadol, MD.

Figure 4. Pterional craniotomy for large olfactory groove meningiomas. (A) Deep-seated

356 location of large olfactory groove tumor. (B) Early identification and dissection of the arachnoid 357 plane between the tumor capsule and the ipsilateral optic nerve, chiasm, and internal carotid 358 artery is a major advantage provided by the pterional approach over bifrontal craniotomy. (C) 359 Early operative view showing the relationship between the tumor capsule, internal carotid artery 360 (ICA), and optic nerve (ON). With permission from The Neurosurgical Atlas by Aaron Cohen361 Gadol, MD. 
Table 1. Advantages and disadvantages of each surgical corridor

\begin{tabular}{|c|c|c|}
\hline Novel Operative Corridor & Advantages & Disadvantages \\
\hline \multirow[t]{3}{*}{$\begin{array}{l}\text { Contralateral PITTA for accessing } \\
\text { periatrial region of the lateral } \\
\text { ventricle }\end{array}$} & $\begin{array}{l}\text { Minimizes retraction on } \\
\text { ipsilateral central lobule }\end{array}$ & $\begin{array}{l}\text { Less familiar operative } \\
\text { anatomy, particularly for } \\
\text { vascular structures }\end{array}$ \\
\hline & $\begin{array}{l}\text { Provides favorable cross- } \\
\text { court view of laterally } \\
\text { projecting lesions }\end{array}$ & $\begin{array}{l}\text { Places the normal contralateral } \\
\text { hemisphere at risk }\end{array}$ \\
\hline & $\begin{array}{l}\text { Inferior approach allows for } \\
\text { early control of the vascular } \\
\text { pedicle }\end{array}$ & \\
\hline \multirow[t]{2}{*}{$\begin{array}{l}\text { Paramedian SCTT approach to the } \\
\text { posterior mediobasal temporal } \\
\text { region }\end{array}$} & $\begin{array}{l}\text { Minimizes risk to } \\
\text { supratentorial structures }\end{array}$ & $\begin{array}{l}\text { Longer working distances } \\
\text { compared to those of the } \\
\text { transsylvian or transcortical } \\
\text { routes }\end{array}$ \\
\hline & $\begin{array}{l}\text { Eliminates need for lateral } \\
\text { temporal corticotomy }\end{array}$ & $\begin{array}{l}\text { Poor access to lesions situated } \\
\text { anterior to the uncus }\end{array}$ \\
\hline \multirow[t]{3}{*}{$\begin{array}{l}\text { Lateral (paramedian) } \\
\text { supracerebellar infratentorial } \\
\text { approach to the midline pineal } \\
\text { region }\end{array}$} & $\begin{array}{l}\text { Decreases risk to midline } \\
\text { vermian and paravermian } \\
\text { bridging veins }\end{array}$ & $\begin{array}{l}\text { Potentially worse access to } \\
\text { large bilateral lesions }\end{array}$ \\
\hline & $\begin{array}{l}\text { Minimizes necessary } \\
\text { cerebellar retraction }\end{array}$ & $\begin{array}{l}\text { Disorienting oblique trajectory } \\
\text { is less familiar than the midline } \\
\text { approach }\end{array}$ \\
\hline & $\begin{array}{l}\text { Exposes only } 1 \text { cerebellar } \\
\text { hemisphere and transverse } \\
\text { sinus }\end{array}$ & \\
\hline \multirow[t]{3}{*}{$\begin{array}{l}\text { Pterional craniotomy for large } \\
\text { olfactory groove meningiomas }\end{array}$} & $\begin{array}{l}\text { Risks limited to single } \\
\text { hemisphere (typically } \\
\text { nondominant) }\end{array}$ & $\begin{array}{l}\text { Less generous exposure, } \\
\text { particularly for lesions with } \\
\text { extensive bony invasion }\end{array}$ \\
\hline & $\begin{array}{l}\text { Provides early identification } \\
\text { and protection of key } \\
\text { neurovascular structures }\end{array}$ & \\
\hline & $\begin{array}{l}\text { Spares the frontal sinuses } \\
\text { and anterior portion of the } \\
\text { superior sagittal sinus }\end{array}$ & \\
\hline
\end{tabular}

Abbreviations: PITTA, posterior interhemispheric transfalcine transprecuneus approach; SCTT, supracerebellar transtentorial. 

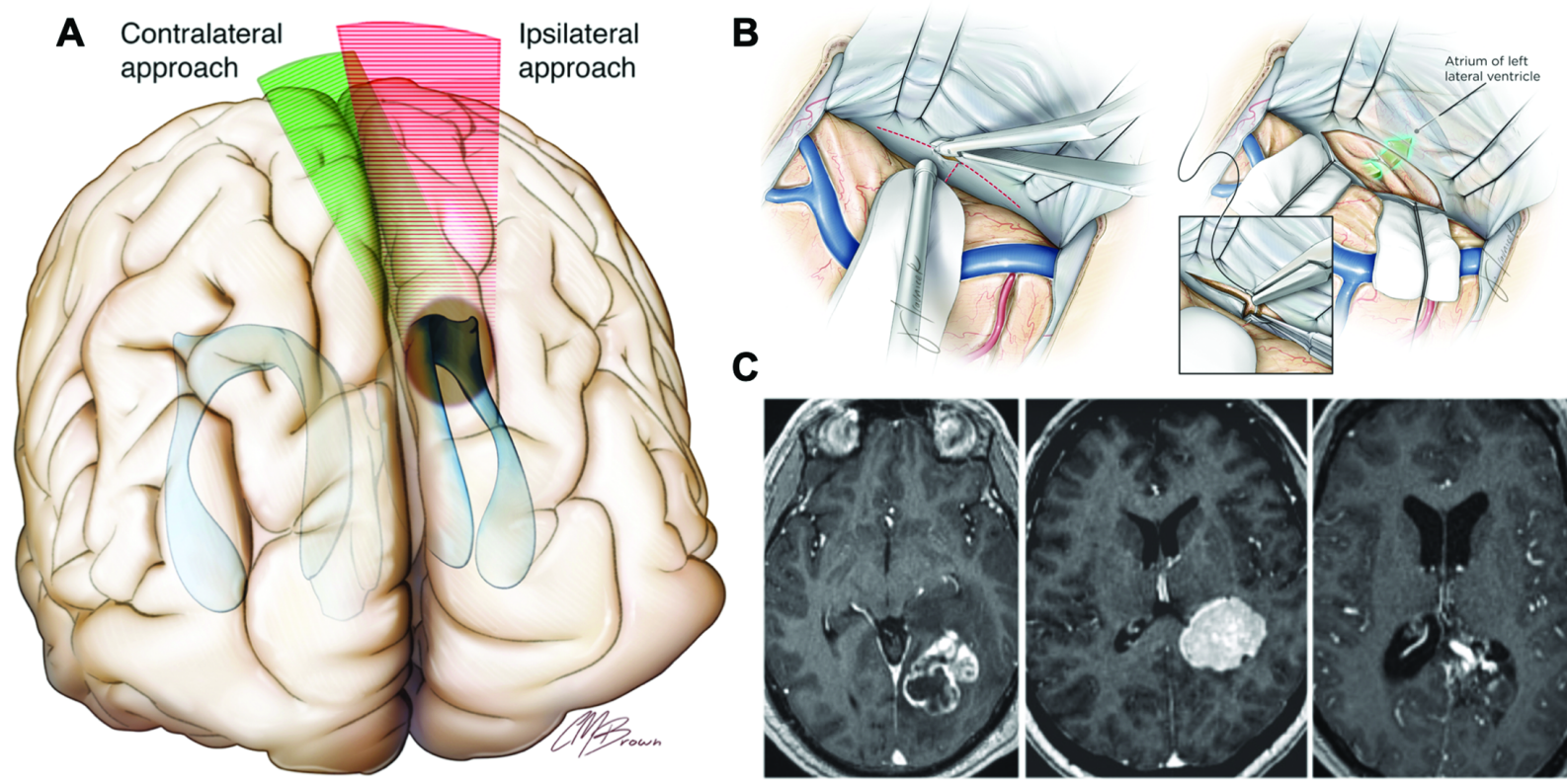
A Paramedian supracerebellar transtentorial corridor

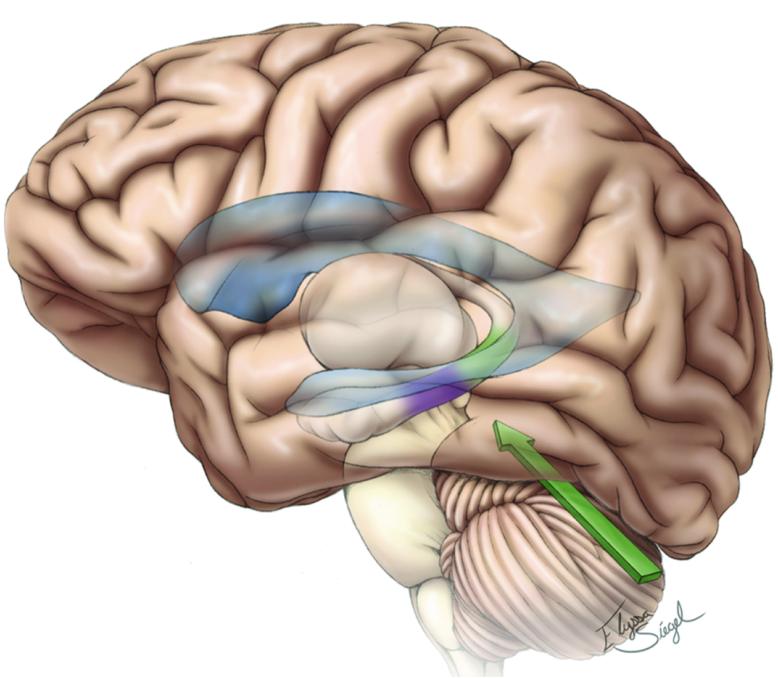

B

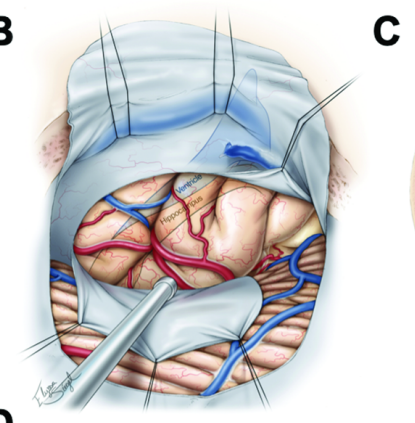

C

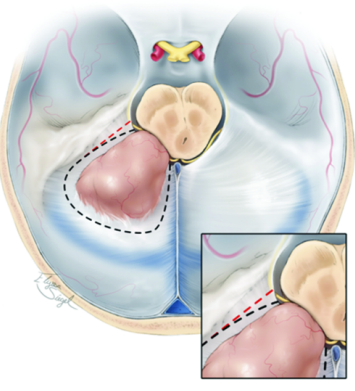

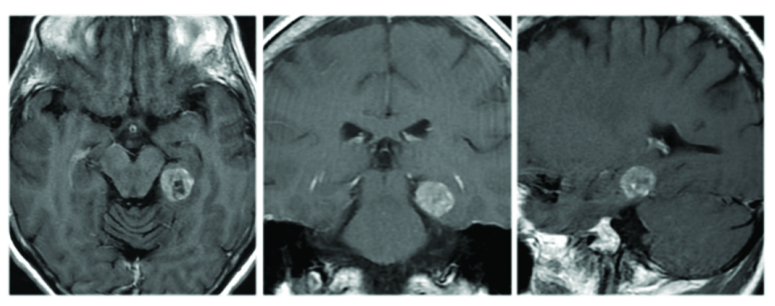


A Lateral (paramedian)

supracerebellar infratentorial approach to midline pineal region

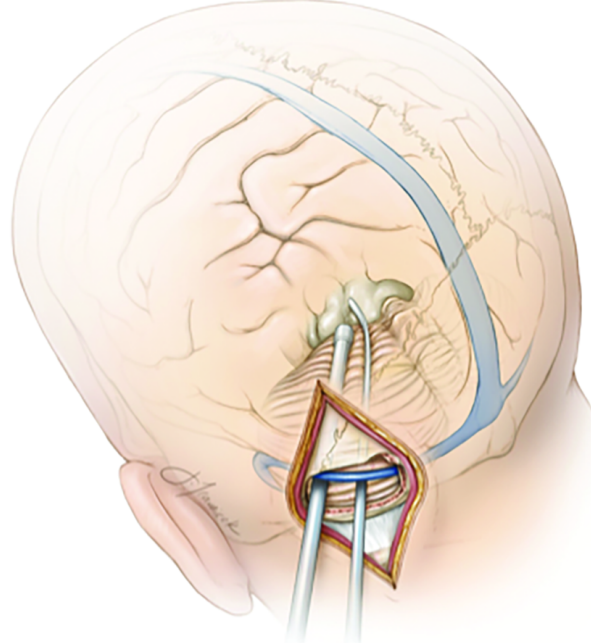

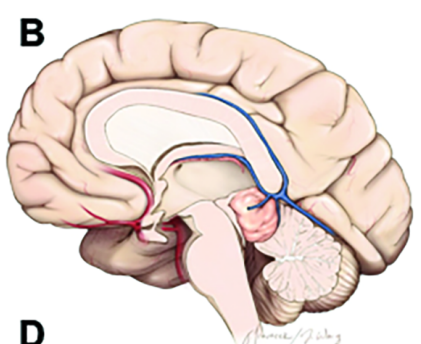
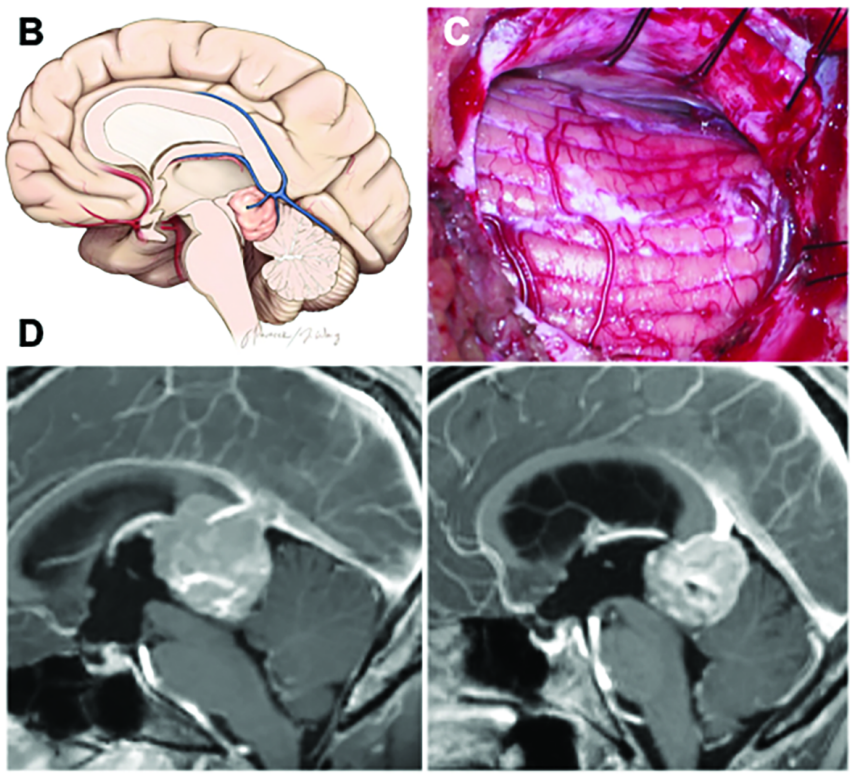

E
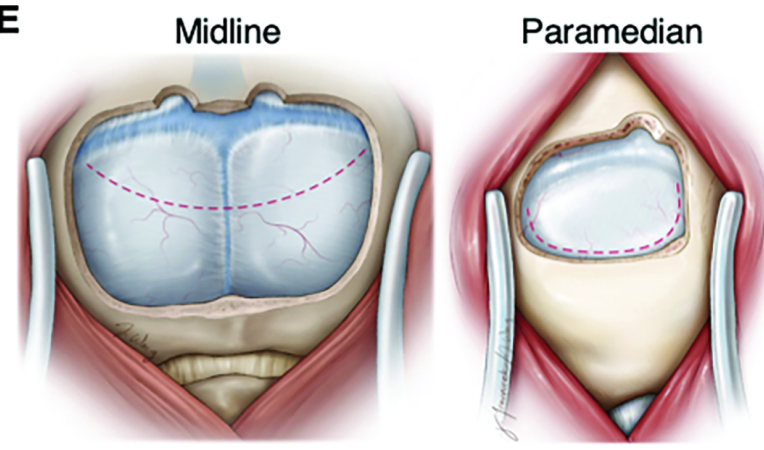

F Midline
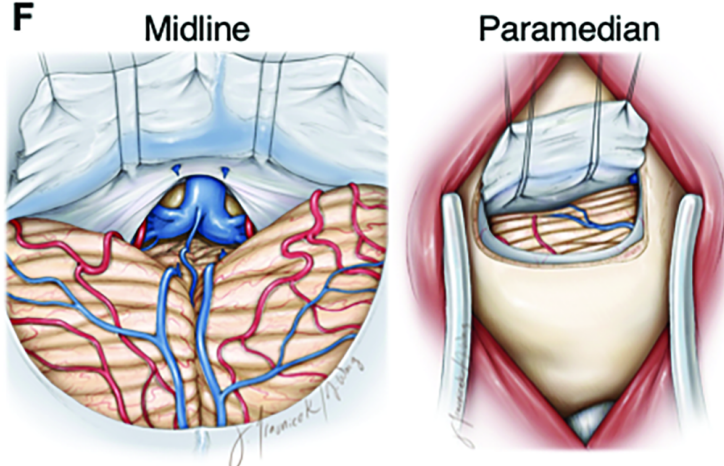

G

Midline
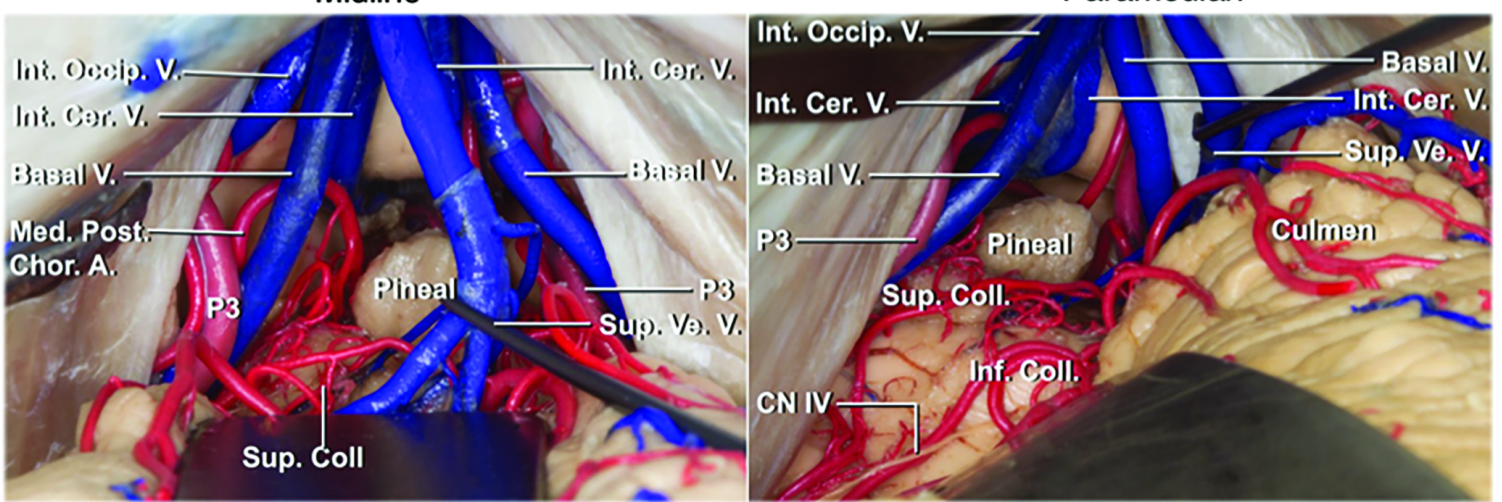

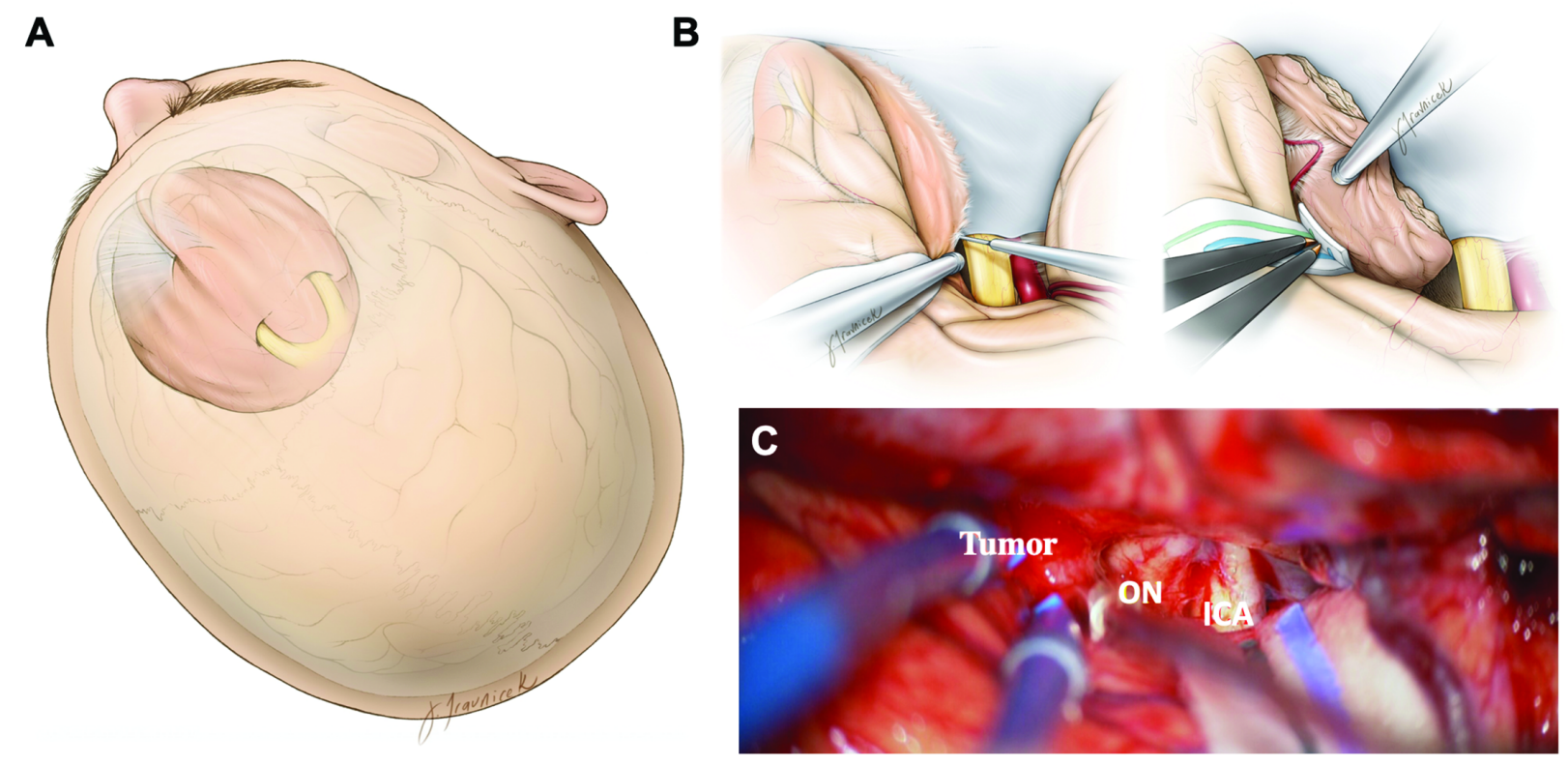